\title{
Entre a liberdade e a igualdade: princípios e impasses da ideologia poliamorista*
}

\begin{abstract}
Antonio Pilão**
Resumo

O objetivo principal deste artigo é analisar a articulação entre os ideais de liberdade e igualdade nos discursos de "poliamoristas" brasileiros sobre amor e sexualidade. "Poliamor" é o nome "nativo" dado à possibilidade de estabelecer mais de uma relação amorosa ao mesmo tempo com a concordância de todos os envolvidos. A pesquisa foi conduzida a partir da análise de quatro redes virtuais "poliamoristas", dos discursos obtidos a partir de cinco entrevistas em profundidade realizadas com adeptos do "poliamor" e da observação participante conduzida em "poliencontros".
\end{abstract}

Palavras-chave: Conjugalidade, Gênero, Sexualidade, Não monogamia, Poliamor.

* Recebido para publicação em 8 de fevereiro de 2013, aceito em 20 de janeiro de 2015.

** Doutorando em Antropologia no Programa de Pós-Graduação em Sociologia e Antropologia na Universidade Federal do Rio de Janeiro - UFRJ, Rio de Janeiro, Brasil.tonipilao@gmail.com 
392 Entre a liberdade e a igualdade

Between Freedom and Equality: Principles and Impasses of Polyamorous Ideology

\begin{abstract}
"Polyamory" is a native name given to the possibility of establishing more than one loving relationship at the same time with the agreement of everyone involved. The main objective of this paper is to analyze the articulation between the ideals of freedom and equality in the discourses of Brazilian "polyamorists" about love and sexuality. The research was conducted through the analysis of four "polyamorous" virtual networks, five interviews with supporters and participant observation in "polymeetings".
\end{abstract}

Key Words: Conjugality, Gender, Sexuality, Non-monogamy, Polyamory. 


\section{Introdução}

Poliamor $^{1}$ é uma categoria nativa que designa a possibilidade de se estabelecer simultaneamente mais de uma relação amorosa com a concordância dos envolvidos. Segundo o blog Poliamores ${ }^{2}$, existem basicamente três tipos de arranjos poliamoristas: a "relação em grupo", quando todos os membros do arranjo têm relações amorosas entre si; a "rede de relacionamentos interconectados", quando cada membro tem relacionamentos poliamoristas distintos daqueles dos parceiros; $e$ a "relação mono/poli", quando, em um casal, um dos parceiros é poliamorista e o outro, por opção, não é. Os modelos se dividem em "aberto" e "fechado". No primeiro caso, está colocada a possibilidade de novos amores e, no segundo, é praticada a "polifidelidade", restringindo as experiências amorosas àquelas já existentes.

O termo poliamor é uma combinação da expressão grega poli (vários ou muitos) com a latina amor. De acordo com Cardoso (2010), teria surgido em agosto de 1990, em um evento público em Berkeley (Califórnia), em que "neopagãos", pertencentes à Igreja de Todos os Mundos ${ }^{3}$, buscavam criar um Glossário de Terminologia Relacional. Com bases espiritualistas e pagãs, essa é considerada pelo autor como a primeira vertente poliamorista. Um dos livros mais conhecidos sobre o poliamor, Polyamory: The New Love Without Limits, escrito por Deborah Anapole publicado em 1997, faria parte dessa primeira tendência.

Cardoso (2010) argumenta que, naquele momento, não teria havido grande circulação do termo, favorecendo um segundo surgimento, dessa vez com um viés menos "transcendentalista" $e$

\footnotetext{
1 Apesar de se tratar de uma categoria nativa, optei por não utilizar aspas durante o texto.

2 Texto publicado em [http://poliamores.blogspot.com.br/] no dia 05 maio 2009 e consultado pela última vez no dia 19 dez 2012.

3 A Igreja, inspirada na obra de ficção Stranger in a Strange Land de Robert Heinlein, foi formada em 1962 nos Estados Unidos. Disponível em: $<$ http://www.caw.org/>.
} 
mais "cosmopolita", pretendendo ajudar a solucionar problemas práticos dos relacionamentos amorosos. Em 20 de maio de 1992, em um grupo de discussão pela internet, o termo poliamor ressurgiu como sinônimo de "não monogamia", sendo criado, em seguida, o primeiro grupo de e-mails destinado a discuti-lo, o alt.polyamory.

Desde seu surgimento, a internet é o principal veículo de interação entre poliamoristas, o que favoreceu a internacionalização de suas propostas. ${ }^{4}$ Hoje, são mais de 20 países ${ }^{5}$ com grupos que se destinam a trocar experiências pessoais sobre poliamor, promover visibilidade e conquistar direitos, como a legalização das uniões poliamorosas.

No Brasil, a comunidade Poliamor Brasil da rede de relacionamentos Orkut, criada em 2004, com aproximadamente 1800 membros, era o grupo de discussões mais antigo e numeroso no período de realização da pesquisa de dissertação (2011-12) que originou este artigo. Em 2008, 2009 e 2011 foram criados, respectivamente, os sites http://poliamorbrasil.org/, o blog http://poliamores.blogspot.com/ e o grupo Pratique Poliamor Brasil, este último no Facebook, com cerca de 500 participantes. $^{6}$

4 Com exceção dos países de língua portuguesa e espanhola que utilizam o termo poliamor e os de língua francesa que traduziram para polyamour, os demais mantiveram o uso do original, polyamory.

5 Eles se situam, sobretudo, nos Estados Unidos e Europa: Alemanha, Reino Unido, França, Espanha, Portugal, Áustria, Dinamarca, Irlanda, Holanda, Suíça etc. Há também grupos no México, Canadá, Japão, África Do Sul, Austrália, Nova Zelândia, Brasil, dentre outros [http://www.polyamory.org/SF/groups.html último acesso em: 20 abril 2015].

6 Em pesquisa realizada em 2011, em queforam analisados 80 perfis de membros ativos dos grupos do Facebook e do Orkut, 55\% eram homens e 45\% mulheres; São Paulo (31\%), Rio de Janeiro (24\%), Rio Grande do Sul (7\%) e Brasília $(7 \%)$ foram os estados de moradia mais citados; $71 \%$ declararam ter entre 18 e 39 anos; 87\% afirmaram ter cursado ou estar cursando universidade; $55 \%$ das mulheres e $25 \%$ dos homens se definiram como bissexuais, $55 \%$ dos homens e $20 \%$ das mulheres como heterossexuais. Quanto à religiosidade, espitualidade: "Ateu"/"agnóstico"(40\%), "com um lado espiritual independente de religiões" (32\%) e "pagão/ "neopagão" (7\%). 
Os principais temas debatidos nesses sites são: o fracasso da monogamia e a afirmação da superioridade do poliamor; as diferenciações e hierarquias relacionadas a outras formas de conjugalidade; e os desafios enfrentados para a vivência do poliamor.

Proponho neste artigo analisar os discursos referentes a dois ideais amorosos e sexuais dos "poliamoristas" brasileiros: liberdade e igualdade, dando especial destaque à forma como eles se articulam, gerando, além de complementariedade, tensões $e$ impasses. As reflexões aqui desenvolvidas são resultado da reformulação da pesquisa realizada para minha dissertação de mestrado (Pilão, 2012), em que foram analisadas a composição de quatro redes virtuais de poliamor brasileiras ${ }^{7}$, os discursos obtidos a partir da realização de cinco entrevistas em profundidade com poliamoristas $^{8} e$ observações obtidas através de minha participação nos chamados poliencontros.

\section{A identidade poliamorista}

O poliamor é apresentado pelos pesquisados como uma alternativa crítica à monogamia. Há, no entanto, uma divergência fundamental entre seus defensores. Para alguns, a monogamia não é necessariamente uma obrigação e um mal a ser combatido. Enquanto, para outros, não há escolha pela monogamia, já que ela é o único modelo de relação socialmente legítimo. No primeiro

7 [http://poliamorbrasil.org/], [http://poliamores.blogspot.com/], comunidade Poliamor Brasil na rede de relacionamentos Orkut, e a Pratique Poliamor Brasil no Facebook.

${ }^{8}$ As entrevistas foram realizadas no ano de 2011. Rodrigo, 24 anos, estudante universitário, mora com os pais na zona oeste do Rio de Janeiro; Lucas, 37 anos, funcionário público, mora com a mãe e a irmã na zona norte do Rio de Janeiro; Roberta, 26 anos, estudante universitária, mora com os pais em Niterói, município do estado do Rio de Janeiro; Alice, 30 anos, professora, mora com a filha na região serrana do Rio de Janeiro. A quinta entrevista foi realizada com a autora do site Poliamor Brasil. A fim de garantir o anonimato, todos os nomes foram substituídos. 
caso, a busca é por "igualdade" entre todas as formas de conjugalidade; já no segundo, a ênfase está na "diferença", afirmando a superioridade do poliamor e o objetivo de substituir a monogamia por uma nova estrutura legítima de relacionamentos.

Dentre os elementos que permitem diferenciar e hierarquizar as diversas modalidades de conjugalidade estão os valores que formam a base ideológica do poliamor: a "liberdade" e a "igualdade". São eles, ainda, que justificam a opção pelo poliamor em detrimento das demais formas de relacionamento amoroso.

O poliamor é considerado um vínculo mais "livre" do que a monogamia, uma vez que o estabelecimento de um relacionamento não é impeditivo de outros. Enquanto a monogamia é caracterizada como uma "prisão" - já que há uma única relação legítima por vez -, o poliamor seria a libertação de um modelo de relacionamento infantil, repressor e competitivo. $\mathrm{Na}$ perspectiva dos pesquisados, ele seria também mais "igualitário" do que a monogamia, já que ela é considerada "machista", privilegiando os desejos masculinos e tratando as mulheres como "objetos"; seria marcado pelo combate ao "machismo" e a possibilidade de que tanto homens quanto mulheres tenham mais de um amor ao mesmo tempo.

Um dos passos de uma "carreira poliamorista"9 é o momento do conhecimento do termo poliamor, descrito como "libertador" e "revelador" de um novo mundo, o que faz com que os seus defensores desejem dar mais visibilidade ao poliamor, a fim de possibilitar que todos se sintam "livres" para serem "polis". Entretanto, a padronização de uma terminologia e o reconhecimento do pertencimento a um grupo acaba, paradoxalmente, produzindo o efeito contrário, fazendo com que muitos pesquisados se sintam presos a definições e conceitos criados por outros.

9 Utilizo o conceito de "carreira" seguindo Becker (2008) e Goffman (2001), que se referiram a sequências de mudanças necessárias para que um indivíduo se torne, respectivamente, um usuário de maconha e um doente mental. 
Para Reinaldo ${ }^{10}$, membro da comunidade do Orkut, poliamor é "estar absolutamente livre para sentir o que seja, livre de conceitos, de ideias formuladas por outros sobre o sentir e o amar". Ele defende que se fuja da tentativa de classificar tudo, inclusive os sentimentos: "se acontece uma relação (olhar, contato, emoção) logo começa o processo de classificação. O que é isso? Porque sinto isso? Não podemos simplesmente sentir e SER?" Uma relação é poliamorosa, para ele, desde que dê espaço à liberdade e que esteja fora da necessidade constante de ser enquadrada em "moldes estáticos", já que o amor é "completamente dinâmico e mutável".

João ${ }^{11}$ defende uma posição distinta. Para ele, os conceitos ligados ao poliamor devem ser muito bem definidos. Apesar de concordar que toda classificação é uma simplificação da realidade, é a partir dela que as pessoas se entenderiam. Defende, portanto, que padronizando o uso dos conceitos, as ideias podem ser defendidas de forma mais firme, garantindo "a identidade dos afins com a ideia fundamental", permitindo propagar os ideais do poliamor e romper preconceitos.

Alana $^{12}$ fala, na comunidade Orkut, do desserviço prestado pelas conceituações:

Eu me considerava mais poli antes de entrar para um grupo de discussão, porque vivi uma relação "poli" sem stress, sem ter que conceituar e sem ter outras pessoas tentando

\footnotetext{
${ }^{10}$ Utilizo aspas apenas para as informações que são opções dadas pelas redes sociais a fim de diferenciar das descrições que são escritas pelos próprios usuários. Reinaldo declara, na comunidade Orkut, ter 29 anos e ser professor de yoga.

11 João declara ser morador de São Paulo, coordenador da rede Pratique Poliamor Brasil, moderador da comunidade Poliamor Brasil no Orkut, ter 37 anos. Define-se como liberal, libertino, libertário, ateu, orgiasta, quase-escritor, poliamorista, feminista, entusiasta, empático, intenso, paulistólatra, romântico e heterossexual.

${ }^{12}$ Alana declara morar com filhos em cidade desconhecida. Define-se como "multiétnica", com "um lado espiritual independente de religióes", e com visão política "libertária".
} 
padronizar e criar uma tese sócio-política do que eu vivo $e$ faço (...). Homens e mulheres têm de ser livres, chega de pressão para que tenhamos que escolher um rótulo.

Ela discorda do objetivo defendido por João de padronizar os discursos poliamoristas:

Não me interessa muito a questão das nomenclaturas $e$ regras ou de transformar o poli num movimento político $e$ exigir que a sociedade reconheça o casamento poli ou que inventem uma lei para punir pessoas polifóbicas. Gostaria era de ter liberdade de viver meus relacionamentos em paz, sem ter necessidade de validar alguma forma, conceituar $e$ racionalizar muito, para mim chega de teoria... na prática estamos muito distantes do que utopiamos.

Maurício $^{13}$ também questiona a identidade poliamorista e a tentativa do moderador da comunidade de padronizar os conceitos do grupo:

Não sei se quero o carimbo de poliamorista ou outro ista, porque sou quem sou. Andei lendo e relendo muitos tópicos e muitas coisas dizem que eu poderia, sim, me encaixar em mais essa definição. Mas não vem ao caso porque minha tribo é a dos inimigos da normalidade (...) Casovocê [João] tenha um modelo de poliamorista bonitinho que se adeque às suas idealizações poste aqui. Quem sabe alguém tope se adequar, porque eu, caro, não calço bota de ferro de ninguém (comunidade do Orkut).

Há uma crença entre os pesquisados de que categorias são prisões e identidades são ficções perigosas; o que é agravado

${ }^{13}$ Maurício declara ter 49 anos de idade, ser viúvo e solteiro, morar em Bertioga (SP) com seus filhos, ter cursado Letras na USP sem ter concluído e trabalhar com projetos de sustentabilidade. Define-se como afetivo, compreensível, criativo, "libertário ao extremo" e praticamente vegetariano crudívoro. Suas atividades principais relatadas foram: o empoderamento, o autoconhecimento $e$ a poesia. 
quando são vistas como impostas. Há, dessa forma, um paradoxo na construção das identidades poliamoristas, em que simultaneamente os sujeitos desejam se afirmar como "autênticos" e "originais", mas, para se representarem socialmente, sentem a necessidade de se afirmarem como um grupo, o que, por sua vez, rompe com sua singularidade. Alice expressa essa dificuldade com precisão. De um lado, é contrária ao emprego de "rótulos": "Desprezo efetivamente tudo o que tenta me rotular, me petrificar, me inferiorizar ao nível de uma "coisa"'. E, de outro, vê a organização coletiva como indispensável para ter liberdade para viver o poliamor:

Não gosto muito de definições, rótulos, mas ultimamente eu tenho visto uma necessidade política disso, talvez seja um mal necessário que eu me afirme dessa maneira, para que todas as pessoas que estejam envolvidas no processo e que não sabem que existe esse tipo de relacionamento possam também viver de uma forma mais confortável, sejam mais toleradas na sociedade (Alice ${ }^{14}$, entrevistada em setembro de 2011).

A busca por uma identidade poliamorista, utilizando conceitos bem definidos e organizando uma plataforma de objetivos comuns ao grupo, intensificou-se no ano de 2011, quando foi criada a rede Pratique Poliamor Brasil. O grupo, cujo lema é "Apoio, Autoconhecimento e Militância", teve a adesão das autoras do Blog Poliamores e do site Poliamor Brasil e do moderador da comunidade do Orkut. No mesmo ano, João expôs no Orkut a busca por lavrar a primeira escritura de "união poliafetiva" do mundo, alegando já ter o suporte jurídico e estando apenas à procura de pessoas interessadas em formalizar suas uniões. No ano seguinte, ele divulgou no site Poliamor Brasil e no grupo do Facebook que, no dia 13 de fevereiro de 2012, foi finalmente lavrada a "1 ${ }^{a}$ Escritura de União Poliafetiva do Brasil!"

${ }^{14}$ Ver descrição na nota 8. 
entre duas mulheres e um homem, no Tabelionato de Notas de Tupã em São Paulo. ${ }^{15}$

Após a realização das entrevistas com cinco integrantes da rede Pratique Poliamor Brasil, ficou evidente a dificuldade de se atingir o objetivo proposto de unificação da luta pela legitimação do poliamor. As divergências internas paralisaram projetos $e$ levaram ao afastamento de alguns integrantes. A construção de um grupo poliamorista coeso é um grande desafio já que a centralidade no valor da singularidade dificulta o desapego daquilo que os diferencia.

\section{Identidades de gênero: “igualdade" ou "extinção"?}

Simmel (1950, 1971) e Dumont (1985) afirmam que a igualdade é um dos pilares da moderna noção de indivíduo. Para Salem (1989), Goldenberg (2000) e Heilborn (2004), a igualdade seria, no seio das camadas médias urbanas, o valor norteador dos relacionamentos amorosos contemporâneos, regidos pela expectativa de mutualidade e paridade. Barker e Langdridge (2010), Klesse (2011) e Cardoso (2010) defendem, por seu lado, serem justamente essas as principais bases ideológicas do poliamor. Entre os poliamoristas brasileiros, a definição de poliamor pressupõe certa concepção de igualdade, já que o que constitui um relacionamento poliamoroso é a possibilidade de todos os envolvidos terem mais de um relacionamento simultâneo.

\footnotetext{
${ }^{15}$ Trata-se da primeira união estável em grupo que se tem conhecimento no Brasil. No entanto, existem casos de reconhecimento de duas uniões diferentes $e$ concomitantes [http://s.conjur.com.br/dl/sentenca_poliamorismo.pdf-]. A união em grupo citada apenas começou a ser conhecida a partir de sua divulgação no site do Instituto Brasileiro de Direito da Família (IBDFAM), no dia 21 de agosto de $2012 \quad$ [http://www.ibdfam.org.br/novosite/imprensa/noticias-doibdfam/detalhe/4862] e nos dias 22 e 23 de agosto [http://www.correiobraziliense.com.brapp/noticia/politica-brasileconomia/33,65,33,12/2012/08/22/interna_brasil,318640/uniao-afetiva-entretres-pessoas-e-oficializada-em-escritura-publica.shtml] [http://g1.globo.com/sp/bauru-marilia/noticia/2012/08/uniao-estavel-entre-trespessoas-e-oficializada-em-cartorio-de-tupa-sp.html].
} 
O "machismo" é considerado uma característica própria à monogamia e à poligamia, sendo consensualmente criticado pelos pesquisados. Duas são as divergências encontradas no grupo em relação ao tema. A primeira, em torno da definição das responsabilidades e dos prejuízos, e a segunda, sobre as estratégias de combate.

Maria $^{16}$ e Alana responsabilizam os homens pelo "machismo". A última declara: "homens querem ser poli com a mulher dos outros. Infelizmente muitos não sabem lidar com a mulher de igual para igual... ou a veem como mãe ou como objeto." Andressa ${ }^{17}$ acha que é fácil para o homem ser "poli". Thiago ${ }^{18}$, Rodrigo e Reinaldo discordam: o primeiro diz que a dominação entre os sexos é restritiva para ambos, e o último, que os homens também são prejudicados pelo "machismo":

\section{(...) Somos ensinados a não chorar, a não demonstrar fraqueza, e principalmente a COMPETIR. Logo, eu tenho que ser mais viril, mais "esperto", melhor de cama e dar mais prazer à mulher que qualquer outro homem. (...) Pra uma criança educada nesses termos, se abrir para o amor de forma mais ampla, ou seja: Se eu amo uma pessoa eu quero que ela seja Livre é bem difícil (...) (Reinaldo, comentário na comunidade do Orkut)}

\footnotetext{
${ }^{16}$ Maria faz parte da comunidade Orkut e declara morar em São Paulo com os filhos, ter curso superior e ser professora. Define-se como "hispânico/latino", "muito liberal, de esquerda", "heterossexual" e com "um lado espiritual independente de religiões".

${ }^{17}$ Andressa, também da comunidade Orkut, declara ser moradora de São Paulo e ter feito os cursos universitários de Letras, Serviço Social e Artes Plásticas. Define-se como amante secreta da vida, missionária, arco Iris, "libertária ao extremo", militante socialista e empresária da área de cosméticos.

${ }^{18}$ Thiago declara, na comunidade Orkut, morar em Belo Horizonte e ter curso superior incompleto pela UFMG. Define-se como anarco-tropicalista, com posição política "libertário ao extremo" e etnia "multiétnico". Suas paixões são híbridos, experimentação, esquizoanálise, sinceridade radical, festa e orgia, contracultura, surrealismo, pós-estruturalismo etc.
} 
João, defensor do feminismo, afirma que só há (poli)amor em contexto de igualdade e que os homens são machistas:

Igualdade não é barganha. Igualdade é o mínimo necessário para o estabelecimento de relação, a base a partir da qual se constrói diálogo. Não vamos nos isolar numa bolha e achar que o homem atual não é machista $e$ que não está inserido num contexto de opressão do afeto $e$ da sexualidade. Estamos longe de uma igualdade nos relacionamentos (comentário na comunidade do Orkut)

Maurício defende que reciprocidade é "comércio" e que se deve recusar o generalismo feminista:

Vim aqui novamente recusar o uniforme de representante do mundo macho. Não, não faço parte da regra, também não sou a exceção. Talvez, muitas mulheres não saibam como oprimem os homens diferenciados quando cortam todas as cabeças com a mesma lâmina! (...) Fuzilar todos os homens como tranqueiras incapazes de unirem sexo e afeto fazia mais sentido, hoje não é mais regra. Minha geração sofreu muito por conta desse feminismo de guerrilha. Muitas mulheres perderam o melhor da festa porque foram criadas para competir, não para amar. Trocaram afetividade por poder. Será que feministas de carabina que só enxergam cafajestes em tudo que se move podem dar aula de afetividade? (comentário na comunidade do Orkut)

A divergência exposta acima expressa duas concepções recorrentes no universo "poli": a primeira que utiliza os termos "homem" e "mulher" de forma genérica e abstrata com o argumento de que elas sofrem uma dominação histórica e que, portanto, é necessário identificar os "agressores" e as "vítimas" a fim de lutar por "igualdade". A outra perspectiva critica a utilização desses termos por considerar que são um perigoso englobamento de práticas e indivíduos únicos. Nessa lógica, o feminismo ao invés de aproximar os homens das mulheres, 
acabaria por diferenciá-los ainda mais ao reproduzir uma distinção linguística entre eles.

Na década de 1990, nos Estados Unidos, o mesmo debate em torno das identidades coletivas esteve presente nos movimentos LGBT e feminista. A posição da teoria e da política queer é a de subverter e desestabilizar a dicotomia masculino/feminino, legitimando os trânsitos e o "entre-lugar". Nessa posição, a crítica se concentra sobre o sistema binário de classificação do sexo e do gênero, apontando para a artificialidade $e$ as mazelas trazidas por essas fixações identitárias. Outra posição dentro do movimento LGBT e feminista afirmaria a estabilidade identitária e o binarismo sexual buscando romper apenas com os seus estigmas.

Alice e Roberta dizem que questionaram o seu pertencimento à categoria "mulheres". A primeira, após um período de "crise", diz que iniciou um processo de "libertação" dos valores sociais a fim de assumir o "controle" de "si mesma":

TENHO SEDE DE LIBERDADE. Quero estar comigo, no controle de mim mesma (...). Desprezo efetivamente tudo que tenta me rotular, me inferiorizar ao nível de uma "coisa": não sou homem, não sou mulher, não sou feminina, não sou "coisa" alguma, sou sendo, sou muitas, sou vontade e sou história (Alice ${ }^{19}$, entrevistada em setembro de 2011).

Roberta declara ter questionado a oposição masculino/feminino. Ela participa de debates sobre teoria queer ${ }^{20} e$

\footnotetext{
${ }^{19}$ Ver descrição na nota 8.

${ }^{20}$ Cardoso (2010), Klesse (2006) e Barker e Langdridge (2010) analisaram a relação entre movimento queer e poliamor. Para Cardoso (2010), a aliança se dá no questionamento das "certezas" da identidade. Para Barker e Langdridge (2010), há um potencial queer na prática poliamorista de desestabilização das dicotomias: promíscuo e não promíscuo, amor e sexo, amor e amizade, público e privado e até mesmo poliamor e monogamia. Klesse (2006) minimiza a tendência queer do poliamor, afirmando que são mantidos binarismos identitários, em especial na oposição promíscuos x não promíscuos.
} 
pós-gênero e critica o "feminismo essencialista" por articular identidade de gênero ao "biosexo":

Lutar pela liberdade da mulher em si está fadado ao fracasso, porque se ser mulher é submeter um corpo que tem útero a uma série de processos culturais que transformam esse corpo em mulher, e se o gênero mulher é aquilo que por definição serve ao outro gênero que é o homem, então o próprio processo biopolítico de investimento cultural sobre o corpo uterino, que é o que gera o sujeito mulher, já é dominação. Então a teoria queer ela age sobre a raiz do problema e não sobre o problema tal qual já está estabelecido (Roberta ${ }^{21}$, entrevistada em agosto de 2011)

Ao ser questionada se ela se vê como "mulher", responde que não, e que se considera "transgênero":

Não me identifico com os papéis que são reservados ao meu corpo nessa cultura, apesar de considerar que a indumentária feminina é muito mais interessante, mais colorida que a masculina, o comportamento feminino, os trejeitos, a performance, a prostração[sic] de voz, sempre achei tudo isso um saco, sempre gostei mais de jogar vídeo game e correr na rua, ficar com outros meninos, nunca me identifiquei com a figura da mulher (...) Eu me relaciono com elas de forma a pegar coisas do mundo do modo mais transgressor possível em relação à forma como a sociedade pressupõe a utilização desses objetos.

Para ambas as entrevistadas, assumir a identidade feminina não resulta em benefícios, já que o feminino está associado, dentre outras características, à "dependência", à "fraqueza" e à "submissão". Ambas dizem ter como objetivo serem "elas próprias", e de estarem no comando de "si mesmas" e que isso passa pelo questionamento da divisão binária entre homem $e$

${ }^{21}$ Ver descrição na nota 8. 
mulher $e$ da necessidade de se enquadrarem em uma classificação.

No universo pesquisado, a construção de identidades entre poliamoristas é problemática em razão de objetivarem se "desaprisionar", ou seja, permitir que se possa "ser" o que se deseja sem a necessidade de enquadramentos, fixações $e$ categorizações, consideradas opostas à "liberdade". No entanto, apesar de a identidade feminina ser entendida como inferior $e$ exclusivamente limitadora, assumir-se poliamorista tende a ser visto como um "mal necessário" a fim de atuar politicamente na sociedade, ajudando a legitimar uma alternativa à monogamia.

A crítica ao feminino, analisada a partir do discurso das duas poliamoristas entrevistadas, pode dar uma falsa impressão de um culto ao masculino. No entanto, há uma crítica ainda mais acentuada ao universo masculino, por associá-lo à dominação, à hierarquia, à competição e à ausência de afetividade. Essa visão torna-se mais nítida quando, nas discussões sobre gênero nas redes sociais, é defendido o fim do "patriarcado" e o desenvolvimento de um modelo social focado na feminilidade, portanto, "horizontal", "plural" e "circular", chamado por alguns de "ginocrático" ou "matrista".

Podemos afirmar que a crítica de poliamoristas aos papéis sociais atribuídos a homens e mulheres comporta dois níveis: no primeiro, defende-se o "feminismo" e a conquista de direitos pelas mulheres $e$, no segundo, critica-se a distinção entre "homem" $e$ "mulher" $e$ se luta contra a classificação de pessoas em identidades de gênero. Os termos utilizados para designar essa ruptura são "queer", "transgênero" e "androginia". O último é tema de um fórum de discussão no grupo do Facebook:

Há sinais de que caminhamos para o fim do gênero sexual. A androginia refere-se a uma maneira específica de juntar os aspectos "masculinos" e "femininos" de um único ser humano. É possível que, num futuro não muito distante, com a dissolução da fronteira entre masculino $e$ feminino, as pessoas escolham seus parceiros amorosos e sexuais 
pelas características de personalidade, não mais pela condição de serem homens ou mulheres (Lins, 2010:13).

A partir desse trecho do livro Cama na varanda, de Regina Navarro Lins, Lico $^{22}$ inicia um debate com os demais poliamoristas. Para Rodrigo, esse não é o único caminho e, para Renata $^{23}$ trata-se de um processo lento de transição. Andressa acredita que "tudo pode permanecer igual ou até retroceder". Entretanto, os três consideram essa transformação louvável. Rodrigo diz que acha uma "boa apoiar o processo", Renata que torce pela mudança e Andressa que apoia há anos, tanto a androgenia, quanto o poliamor: "é bom fazer parte deste momento histórico e mais ainda fazer parte ativamente".

$\operatorname{Marcos}^{24}$ concorda que há uma tendência para que as escolhas amorosas sejam feitas levando-se em consideração a personalidade e não o gênero, mas defende a escolha e não a imposição de um novo modelo. Rodrigo diz que "não podemos considerar todas as coisas igualmente válidas", porque assim aceitamos a opinião de machistas, racistas e homofóbicos: "A manifestação da opinião deles destrói vidas, portanto não vale." Para Rodrigo, a importância de se apoiar a luta contra o gênero sexual é por considerá-lo uma limitação, contraditório à liberdade. A posição de Marcos de que toda forma de "expressão verbal" é válida é refutada por Rodrigo que defende que a mera expressão de concepções de gênero é uma opressão:

Eles constituem durante seus discursos a própria opressão, criando categorias de pensamento e funcionamento que são opressores e que afetam os indivíduos em seus íntimos. Isso é o caso do racismo, do machismo e da homofobia,

\footnotetext{
${ }^{22}$ Lico declara ser morador de Caetité (BA), ter 22 anos e ter feito curso universitário na UNEB.

${ }^{23}$ Renata declara ter feito curso universitário na UNEB $e$ viver um "relacionamento sério".

${ }^{24}$ Marcos declara ser morador de Brasília, ter estudado literatura na UNB, ser "humanista secular" com preferência política pela "democracia semidireta".
} 
cujos [sic] dois últimos são fundamentados na ideia de gênero. A COEXISTÊNCIA do gênero com o não gênero não é possível, porque um é a negação do outro; logo, temos que optar coletivamente por um ou por outro. Eu opto pelo segundo.

$\mathrm{Chico}^{25}$ diz não crer que os gêneros deixem de existir, porque os considera indispensáveis: um "reflexo social de um fato biológico". Para ele, tampouco se pode afirmar que todo mundo é potencialmente bissexual, já que há uma "puxada" biológica na atração física. Ele defende que se lute por "igualdade legal e social entre gêneros, mas não por uma hegemonia de interesses $e$ atrações físicas. Cada um escolhendo o que lhe agrada no campo pessoal". Rodrigo argumenta que gênero não é manifestação de uma diferença biológica e que, portanto, não é consequência do sexo. Para ele, as categorias "masculino" e "feminino" são, apenas, formas de categorização das coisas que fazem parte de um repertório coletivo de símbolos e práticas. Diz, ainda, perceber um processo generalizado de desconstrução do gênero em favor de escolhas individuais. Essa desconstrução ocorreria tanto com heterossexuais que fogem dos estereótipos de seus gêneros, quanto com homossexuais que criariam seus próprios moldes de gênero. Para Rodrigo, é fundamental retirar a importância do gênero:

Desmoralizá-lo e torná-lo algo ignorado e esquecido pela maioria. Não acho que é uma coisa rápida nem fácil. Eu, por exemplo, sou hétero e muito ligado ao meu gênero, também tenho o sexo do outro como uma coisa que eu dou importância na minha seleção. Mas acho que mesmo sendo assim, a gente pode achar legal a perspectiva de as pessoas não serem assim no futuro.

\footnotetext{
${ }^{25}$ Não há informações disponíveis sobre esse participante do fórum no Facebook.
} 
A questão que proponho abordar é se o fim do gênero sexual é um objetivo comum a homens e mulheres poliamoristas. Por um lado, pode-se afirmar que sim, já que ambos compartilham da crença de que o gênero é uma limitação a ser combatida. Por outro, é explicito que são as mulheres poliamoristas as que mais enfatizam o anseio pelo seu fim. Um sinal que evidencia essa diferença é a predominância de homens heterossexuais e de mulheres bissexuais, já que como argumentam Butler (2010) e Wittig (1983), a inteligibilidade do gênero está diretamente articulada à heterossexualidade. Os homens poliamoristas, mais "tímidos" na luta contra o gênero sexual, questionam a "masculinidade hegemônica" ao buscarem envolvimentos emocionais profundos e ao defenderem a possibilidade de suas parceiras terem outros relacionamentos.

Apresentei a construção da identidade poliamorista cercada por uma tensão entre a ênfase nas singularidades (postura antiidentitária) e a negação das diferenças em nome da constituição de um grupo de identidade. $\mathrm{O}$ mesmo debate está presente na (des)construção das identidades de gênero. Enquanto alguns pesquisados apresentam uma posição de crítica ao "masculino" $e$ de busca por "igualdade" entre os gêneros, outros criticam a separação de pessoas em duas grandes categorias: "homens" $e$ "mulheres".

\section{Liberdade e igualdade: conciliáveis ou contraditórios?}

Simmel (1971) afirma ter havido duas revoluções individualistas. A primeira, denominada pelo autor de "quantitativa", refere-se à crença na existência de um sujeito universal, natural, e na igualdade fundamental entre todos os seres humanos. O individualismo "qualitativo", por sua vez, ressaltaria o caráter único e singular de cada um, enfatizando o valor da liberdade em seu potencial de produzir diferenciação e relegando a igualdade (em sua dimensão de universalidade), para um segundo plano. Apesar de afirmar uma sequência histórica na emergência dessas duas dimensões do individualismo, Simmel 
argumenta que elas convivem desde o século XIX de forma contraditória no interior das metrópoles.

A divisão proposta por Simmel, entre dois princípios do individualismo, contribui para a compreensão da ideologia poliamorista, cercada por tensões entre as ênfases na "liberdade" e na "igualdade". O conceito poliamorista de "liberdade" refere-se basicamente à dimensão "qualitativa", apesar de apresentar aspectos que vão além da divisão proposta por Simmel. Ele compreende as noções de diferenciação, singularidade, espontaneidade e autonomia. Já o segundo grupo de ideais, reunidos na chave da "igualdade", engloba as noçóes de reciprocidade, equidade, mutualidade, identidade e negociação. $\mathrm{Em}$ suas pesquisas sobre conjugalidade em camadas médias urbanas, Heilborn (2004) argumenta que o "casal igualitário" é guiado por duas forças contrárias: de um lado, o anseio por igualdade que implica "compromisso" e busca de "indiferenciação" ("simbiose") ${ }^{26} e$, de outro, a valorização da singularidade e da liberdade. No mesmo sentido, Féres-Carneiro (2008) afirma ser esse o principal dilema da conjugalidade contemporânea:

O fascínio e a dificuldade de ser casal residem no fato de esta díade encerrar, ao mesmo tempo, na sua dinâmica, duas individualidades e uma conjugalidade (...) Assim, o casal contemporâneo é confrontado, o tempo todo, por duas forças paradoxais. Se por um lado, os ideais individualistas estimulam a autonomia dos cônjuges, enfatizando que o casal deve sustentar o crescimento e o desenvolvimento de cada um, por outro, surge a necessidade de vivenciar a conjugalidade, a realidade

${ }^{26}$ Figueira (1981:128-129) afirma que: "quando se discriminam para serem si próprios, já não podem sê-lo vez que o outro, diluído em sua alteridade, é parte integrante da noção de si próprio, quando se entregam à fusão oceânica... não o conseguem, já que não podem deixar de ser, em alguma medida, algo diferente do outro no qual buscam se diluir". 
comum do casal, os desejos e projetos conjugais (FéresCarneiro, 2008:3).

Para Heilborn (2004), o "casal moderno" reivindica primazia do par sobre outras relações, provocando uma sensação de "aprisionamento sentimental" entre os cônjuges. A autora afirma que a relação dual é composta por "cobranças", "monitoramento" do fluxo de trocas e "reforma do outro" que visam garantir a mutualidade entre os deveres, obrigações e concessões. Nesse plano, as diferenças individuais em certas situações tendem a ser entendidas, segundo a autora, como descompromisso do acordo de cooperação mútua. Para a autora, essa valorização das noções de "unidade", "compromisso" e "igualdade" colide com o "sacrossanto valor da singularidade irredutível do indivíduo" (Heilborn, 2004:148).

$\mathrm{O}$ argumento que defendo a seguir é o de que os poliamoristas pesquisados procuram desfazer a contradição entre conjugalidade e individualidade, uma vez que afirmam a possibilidade de estabelecerem relações conjugais sendo "eles mesmos" e de recusarem a constituição de uma unidade com o parceiro. Nesse sentido, o "nós" se conjugaria com o verbo "estar" e não com o "ser". ${ }^{27}$ Essa dinâmica não significa, entretanto, a negação do vínculo amoroso. Pelo contrário, o poliamor se constitui a partir da defesa de ligações "íntimas" e "profundas", mas com a possibilidade de que elas sejam feitas sem perda de autonomia. Os dispositivos que buscam possibilitar a aliança entre amor e liberdade são a dissolução da regra de exclusividade conjugal, o desenvolvimento do sentimento de "compersão", além da crítica a atitudes percebidas como de "controle" e "expectativa" $e$ a promoção daquelas percebidas como sendo de "tolerância" $e$ "aceitação".

${ }^{27}$ Badinter (1986:267) faz uma afirmação sobre o amor na contemporaneidade pertinente à nossa reflexão: "A tendência atual não está mais ligada à noção transcendente de casal, mas antes, à união de duas pessoas que se consideram menos como as metades de uma bela unidade do que como dois conjuntos autônomos." 
O termo "compersão" é uma tradução do neologismo em inglês "compersion" e é considerado um "novo" sentimento, oposto ao ciúme e fruto de um movimento de superação do sentimento de posse, a partir da aceitação da liberdade de amar do(s) parceiro(s). Brenda, autora do blog Poliamores, descreve esse sentimento como sentir-se feliz com a felicidade do outro: "É ver o amor e carinho que ele(a) sente por outros com bons olhos". Carol, no Orkut, afirma que compersão é: "ficar alegre quando a pessoa que você ama é amada por mais alguém". A versão mais partilhada entre poliamoristas é a de que o surgimento do termo teria ocorrido na comunidade Kerista de São Francisco na década de 1970, da prática de um jogo chamado "ouija board".

O fundamental na proposta poliamorista é desfazer a lógica de que um relacionamento é uma prisão. ${ }^{28}$ Para tanto, torna-se necessário reduzir ao máximo o terreno do interdito, favorecendo atitudes espontâneas, motivo pelo qual, idealmente, um relacionamento poliamorista não deve ser altamente regrado. É possível afirmar que os poliamoristas apresentam uma proposta de gestão das diferenças fundamentalmente distinta das encontradas entre os "casais igualitários". Salem (1989), que analisou a "conjugalidade igualitária" das camadas médias do Rio de Janeiro, fala em uma busca sempre fadada ao fracasso por uma unidade identitária:

O sentido de completude atribuído à união marital impregna os casais ditos modernos; e sua maior propensão a desfazer casamentos (e a buscar outros, note-se bem) não contradita, mas pelo contrário reitera, a incessante busca da completude. Talvez seja inclusive pertinente sugerir que é precisamente na incansável perseguição desse ideal que fundamenta-se sua vulnerabilidade: o casal converte-se em uma unidade tão sobrecarregada de sentidos $e$ de

\footnotetext{
${ }^{28}$ Representação comum entre os participantes de algumas pesquisas sobre conjugalidade que utilizam ainda a expressão coleira para designar a dependência e a falta de liberdade. Goldenberg (2010) e Heilborn (2004) discutem essas representações.
} 
expectativas que não é de todo surpreendente que, nele, seja alta a probabilidade de implosão(Salem, 1989:28).

A diferenciação mais nítida entre o poliamor e essa forma de laço conjugal está na recusa da constituição de uma unidade e de uma identidade comum. Vincula-se, mas se mantêm e se ressaltam as diferenças, a fim de preservar as individualidades não apenas em relação à família (como os "casais modernos"), mas fundamentalmente à própria parceria amorosa. Os poliamoristas definem-se como seres "completos" e que apenas se "complementam" nos outros, não constituindo seus relacionamentos, portanto, uma unidade. Um elemento que ilustra essa tese é a própria concepção, presente no universo "poli", de que a parentalidade e a coabitação não são desejáveis visto que implicariam em perda de autonomia.

Já que o casamento monogâmico é tido como aprisionador e hipócrita e o poliamor é considerado uma forma de conjugar amor e autonomia, as noções de compromisso, responsabilidade e negociação devem ocupar um papel secundário, o que contraria a perspectiva de alguns pesquisadores do tema, que defendem serem essas as principais bases ideológicas do poliamor. Klesse (2011:16) afirma, por exemplo, que, em função dessa prevalência, é difícil associar poliamor e liberdade: "This is why it is difficult to see all aspects of polyamory from a perspective of 'freedom'. At times, poly love can even look like the very opposite of 'freedom'." 29

Entre os poliamoristas pesquisados, percebo uma prevalência oposta - a da liberdade sobre a igualdade - sendo preferível que o outro aprenda a lidar com a sua singularidade ("compersão") do que faça concessões para se "adequar" ao(s) parceiro(s). Por isso, é importante ressaltar que apesar da noção

\footnotetext{
29 "Essa é a razão para a dificuldade de conceber todos os aspectos do poliamor a partir de uma perspectiva de 'liberdade'. Por vezes, o amor poli pode parecer o exato oposto da "liberdade"” (nossa tradução).
} 
de igualdade ocupar um papel central, ela é vista, também, como limitadora da expressão mais autêntica do indivíduo. Sugiro o conceito de "equânime-normatividade" para aludir à percepção crítica de alguns poliamoristas sobre a exigência de igualdade, reciprocidade e mutualidade dentro dos relacionamentos amorosos, por considerarem um mecanismo externo de constrangimento à livre expressão amorosa.

Maurício argumenta que é a herança cristã que faz conceber o amor como um sistema de trocas, no qual se dá o que não se tem, assumindo responsabilidades maiores do que se pode honrar. $\mathrm{O}$ efeito, segundo ele, é a anulação e o endividamento de si. O modelo de casamento cristão é, para ele, uma "fábrica de insatisfeitos" que converte o amor em sacrifício, o que não implicaria mérito, já que isso seria religião e não amor que é livre, espontâneo, e não comércio e escravidão:

\section{VAMOS ACORDAR? NINGUÉM VEIO AO MUNDO A SERVIÇO DE NINGUÉM! Chega de esperar que um mísero ser humano nos dê tudo que sonhamos. Chega de esperarmos do outro o que nós mesmos não somos capazes de nos propiciar. Aliás, chega de idealizar as pessoas e extorquir delas o que sonhamos, atropelando o que têm a dar. E sabe por quê? Porque isso gera uma ansiedade medonha $e$ transforma tudo em julgamento e cobrança (comentário na comunidade do Orkut)}

Negociação, troca e equidade, apontadas por pesquisadores norte-americanos e europeus como a base que fundamenta os discursos e práticas poliamoristas, são vistos aqui como comércio, escravidão e sacrifício. Em contrapartida, o ideal de relação defendido é livre e espontâneo. A defesa de um "amor incondicional", entretanto, não é unânime. Helô, em seu site, defende que este último "cega", encobre vontades e impede reconhecer as razões que nos fazem amar quem amamos $e$ as que nos fazem ser amados. Para Reinaldo e Maurício, o amor é incondicional, e tem de ser diferenciado do comércio: "amor é o que tenho para dar, o que vou receber não pode ser condicional", 
diz Maurício. Ambos defendem a ideia de que não se deve amar em função do amor do outro, porque isso implica em tentativa de controle. Nessa lógica, cada um oferece o que pode, e cabe a quem recebe aceitar o que ganha ou seguir adiante. Ao conceber as relações amorosas como trocas seriam criadas "dívidas", já que as partes seriam estimuladas a dar o que não têm. É a essa forma de amor que ambos se opõem, defendendo, em contrapartida, um laço baseado na tolerância e na aceitação da liberdade e da singularidade do amado.

A discussão do amor como uma forma de relação calcada no princípio de reciprocidade remete às reflexões de Mauss (1974) e Lévi-Strauss (1976). O discurso poliamorista que enfatiza a liberdade defende o indivíduo "fora do mundo" - que não atende a normas sociais, a constrangimentos, hierarquias e relações de poder. O relacionamento amoroso é descrito como emancipado do social, fruto inequívoco e exclusivo dos desejos absolutamente singulares dos envolvidos. A igualdade e a reciprocidade são ideais desvalorizados por esses poliamoristas, por se tratarem de princípios reguladores das afetividades, razão pela qual cunhei o conceito de equânime-normatividade para descrever a aversão de parte dos poliamoristas pesquisados a esses princípios.

Há dentre eles, em contrapartida, os que defendem que o amor deva ser regido por princípios de reciprocidade, ressaltando que existem condições necessárias para a perpetuação do vínculo amoroso. Regras são, portanto, criadas a fim de gerir a relação. Abre-se também espaço para acordos, concessões e disputas entre os envolvidos. Entre os que defendem o "amor incondicional", a crença é que o amor não pode ser regrado, concedido ou constrangido. "Discutir a relação", apontada por Barker (2005), Klesse (2006, 2011) e Cardoso (2010) como marca dos vínculos poliamoristas, é vista nessa perspectiva como quebra de espontaneidade e liberdade, uma vez que o amor não pode estar sujeito a negociações e concessões, entendidas como "sacrifícios" e "anulação de si": 
Para mim NÃO vale a pena se prender a quem não quer caminhar na mesma direção. Já fiz isso e o resultado final foi dor e sofrimento. Conheço pessoas que declaradamente abriram mão de muitas coisas em que acreditavam pelo "limite" do parceiro... Mas quando olho pra essas pessoas sempre tenho a sensação de que elas estão um pouco apagadas... Que elas não brilham mais como antes (Reinaldo, comentário na comunidade do Orkut).

Maurício reforça o argumento de Reinaldo:

Quando limites começam a se tornar limitações, cada um deve procurar sua turma. $\mathrm{Na}$ "economia" afetiva barganhar potenciais de crescimento é sempre um nivelamento por baixo. Poliamor, para mim, serve justamente para isso, para que não tenhamos que ser a única fonte de ninguém, nem extrair exclusivamente de um, tudo o que podemos querer... (comentário na comunidade do Orkut).

São diversas as soluções encontradas para o impasse entre a valorização de um vínculo livre e espontâneo conjugado a um outro recíproco e equânime, mas o que considero importante destacar é que no poliamor brasileiro não há, como argumentam os pesquisadores do tema ${ }^{30}$, uma defesa homogênea da mutualidade, pois há, antes disso, valores ainda mais centrais em seus discursos: liberdade e autenticidade.

O único aspecto que unifica os poliamoristas é a defesa da possibilidade do estabelecimento de mais de uma relação amorosa ao mesmo tempo. Para alguns, o modelo defendido é aquele praticado por Simone de Beauvoir e Sartre, com uma distinção

\footnotetext{
${ }^{30}$ Alguns autores que enfatizam essa dimensão são Anapol (2010), Barker e Langdridge (2010) e Klesse (2011:5). Este último afirma que: "As a consensual approach to non-monogamy, polyamory promotes an ethics based on honesty, respectful negotiation and decision making, integrity, reciprocity and equality" ("Como uma abordagem consensual da não-monogamia, o poliamor promove uma ética baseada em honestidade, negociação e decisão respeitável, integridade, reciprocidade e igualdade" [nossa tradução]).
} 
qualitativa entre os relacionamentos - "amor necessário" e "amor contingente". Entre os pesquisados, essa ideia aparece nas categorias "relação primária" e "relação secundária". Outros limitam a possibilidade de amores, vivendo uma polifidelidade. Essas duas formas, apesar de expostas nas redes sociais, são muito pouco defendidas. A centralidade do valor da liberdade implica o anseio pela possibilidade de amores tão intensos quanto os anteriores. A polifidelidade, assim como a hierarquização entre os relacionamentos, é vista como um resquício monogâmico, por ser contrária aos dois principais valores poliamoristas: a igualdade e a liberdade.

$\mathrm{Na}$ ideologia poliamorista, as diferenças entre os parceiros $e$ entre as parcerias são afirmadas, ao mesmo tempo em que as hierarquias são recusadas. A igualdade deve ser acompanhada pelo reconhecimento e culto das diferenças já que só há razão para se viver ilimitados amores porque eles são diferentes entre si. Por outro lado, não faz sentido escolher um único amor já que eles não são hierarquizáveis. A distinção feita pelos pesquisados entre seus amores procura recusar as dualidades: superior $e$ inferior; mais importante e menos importante; primário e secundário; escolhido e descartado. Acredita-se que ninguém deve, necessariamente, reunir todas as qualidades do mundo, pois cada um tem seus próprios atributos, sendo únicos e especiais a seu modo. É essa singularidade o que os pesquisados dizem buscar nos relacionamentos.

Cabe destacar que os termos hierarquia, autoridade, poder e controle são vistos como próprios da sociedade atual, capitalista, cristã e monogâmica. O poliamor é associado a outro tipo de sociabilidade, não competitivo, tolerante, cooperativo e não hierárquico. No XII Poliencontro do Rio de Janeiro, realizado em 24 de julho de 2011, foi defendida a ideia de que a monogamia é a expressão de um sistema social que incentiva a competição entre os indivíduos, em que todos devem escolher uma única pessoa e a afetividade de uns pelos outros seria concorrente e excludente. $\mathrm{O}$ controle sobre os parceiros incidiria sobre a tentativa de não perder o lugar de escolhido de alguém. Rodrigo, presente no 
evento, defendeu que na monogamia: "Você tem que controlar a afetividade do outro para que ele não te substitua, só que você não quer que ele restrinja a sua. Eu costumo ouvir: 'se eu pudesse ter poliamor só para mim e não pro meu parceiro seria ótimo"'.

Segundo ele, essa dinâmica acaba criando uma relação de disputa no casal, ambos buscando mais liberdade e restrição à liberdade do parceiro. $\mathrm{O}$ poliamor visaria, segundo os poliamoristas presentes no encontro, desestimular tanto a competição por parceiros quanto entre parceiros.

$\mathrm{O}$ "culto" poliamorista às idiossincrasias individuais caminha junto a uma percepção de igualdade entre essas singularidades, expressa por Maurício ao grupo do Orkut: "Somos feitos da igualdade mais libertária que existe, a diferença". Assim, para ele, a única forma de expressão possível de igualdade é na diferença, uma vez que o foco poliamorista está em revelar seu "eu mesmo", o que passa necessariamente por um processo de distinção.

\section{Considerações finais}

Críticas à monogamia são antigas $e$ bem numerosas na história do Ocidente. A partir de Ellis (1927) e Westermarck (1936),é possível observar que até o século XIX predominava entre médicos e ideólogos a defesa da legalização da poliginia, mas raramente da poliandria. Nesse sentido, dizia-se ser preferível um homem ter mais de uma esposa oficial de modo a, simultaneamente, atender a natureza sexual masculina não monogâmica e combater as mazelas da prostituição, do adultério e do concubinato.

No século XIX, sob forte influência do anarquismo e do socialismo, foram formuladas algumas críticas à monogamia, pautadas no ideal de igualdade entre homens e mulheres, dentre elas as de Charles Fourier, Robert Owen e Frances Wright. Ainda assim, cabe destacar que o centro norteador do "amor livre", não era a crítica à monogamia, mas a possibilidade de escolha conjugal, do divórcio e da não interferência da Igreja e do Estado na vida sexual de homens e mulheres. Desse modo, a monogamia 
não ocupa, nesse momento, o mesmo papel de centralidade entre os defensores do "amor livre" do que entre os poliamoristas pesquisados.

$\mathrm{Na}$ passagem do século XIX para o XX,tornou-se praticamente insustentável a defesa do privilégio masculino de ter mais de uma esposa ou parceira sexual. O amor recíproco e monogâmico ocupou um lugar destacado na legitimação dos vínculos conjugais ocidentais modernos em oposição à poliginia das sociedades tidas como menos civilizadas. $\mathrm{O}$ elemento principal de distinção estava na igualdade entre os cônjuges na monogamia ocidental em oposição à condição de quase escravidão a que estariam submetidas as várias esposas de um polígamo (Morgan, 1944; Wake, 1889 e Westermarck, 1891). Desse modo, até os anos 1970, o amor monogâmico mútuo serviu como meio de afirmação da superioridade moral europeia, quando então uma nova onda de discursos críticos à monogamia ganhou intensidade (Sussman, 1975; Marciano, 1975; Libby e Whitehurst, 1977). Dessa vez, a defesa da superação da monogamia não estava mais restrita aos homens ou a posições políticas radicais. As manifestações não monogâmicas como o "casamento aberto", proposto inicialmente por Nena e George O`Neill (1972), atingiram as camadas sociais mais altas e foram representadas positivamente nos meios de comunicação de massa, sobretudo, nos Estados Unidos (Marciano, 1975).

O que difere o poliamor do casamento aberto propagado nos anos 1970 é, em primeiro lugar, a ênfase dada ao amor em detrimento da liberdade sexual. Em segundo lugar, as relações conjugais poliamoristas não são necessariamente diáticas $e$ heterossexuais, podendo envolver três ou mais pessoas, preferencialmente em arranjos bissexuais. $O$ poliamor, diferentemente do casamento aberto, é marcado pelo desenvolvimento de uma identidade, expressa na adoção do termo poliamorista para referir-se aos adeptos, além do uso de símbolos e bandeiras e a organização de grupos poliamoristas com o intuito de buscar legitimar socialmente a prática. 
Procurei mostrar neste trabalho que os ideais que justificam a prática do poliamor são principalmente a liberdade e a igualdade, que mantêm entre si relações de complementaridade, mas, sobretudo, de tensão. Uma delas está em como conjugar liberdade e singularidade à identidade. Há poliamoristas que recusam quaisquer identidades considerando-as prisões, padronizações desnecessárias e perigosas. E ainda, os que afirmam a importância de serem desconsideradas as singularidades a fim de buscarem uma identidade como grupo. Enquanto as identidades de gênero são as mais questionadas, a poliamorista atrai maior adesão. Uma explicação possível para tal diferença é que a identidade poliamorista é entendida como libertadora, tendo como principal objetivo questionar as limitações impostas pela mononormatividade, pela heteronormatividade $e$ pelo machismo. Afirmar-se poliamorista não é, nessa ótica, visto como aprisionar-se, mas defender a libertação do amor, para que ele possa ser experimentado independentemente dos sexos dos envolvidos e da existência de outros relacionamentos.

Outra tensão está em como conciliar individualidade $e$ conjugalidade. Os poliamoristas pesquisados defendem que, no poliamor, não há contradição entre elas, uma vez que é possível estabelecer um vínculo amoroso sem que isso gere impedimentos e constrangimentos aos parceiros. É defendida a possibilidade de amar sendo "si mesmo". Para tanto, é fundamental o desenvolvimento do sentimento de compersão, atitude de aceitação e de contentamento com a liberdade do parceiro. Como a ênfase dos pesquisados está em suas individualidades, é recusado o ideal de fusão com o amado, considerado uma alienação própria da monogamia.

O dilema mais fundamental da prática poliamorista se dá entre, de um lado, a valorização dos princípios de espontaneidade $e$ liberdade e, de outro, os de reciprocidade e mutualidade. Em um extremo, defende-se que não devem existir regras nos relacionamentos, que o amor deve ser espontâneo e que "reciprocidade é comércio". Em outro, prioriza-se a equidade nas trocas, argumentando que um relacionamento deve ser negociado 
e consensual. Enquanto Klesse (2011), Barker e Langdridge (2010) e Cardoso (2010), que pesquisaram o poliamor nos Estados Unidos e Europa, afirmam a predominância entre seus pesquisados dos valores de compromisso, responsabilidade $e$ negociação, entre os poliamoristas brasileiros percebo a prevalência oposta, isto é, da liberdade e da espontaneidade.

Por fim, destaca-se o conflito entre hierarquia $e$ horizontalidade. Há poliamoristas que defendem a necessidade de definir algumas práticas e valores como superiores a outros. São, em geral, as práticas mais igualitárias e libertárias as consideradas melhores: como o poliamor e a bissexualidade. A monogamia e o heterossexismo seriam "inferiores". Por outro lado, há pesquisados que negam qualquer forma de hierarquização, ressaltando a igualdade entre todas as formas de conjugalidade e afetos. Uma hierarquia, em geral, questionada é a entre amores, sendo defendida a possibilidade de estabelecer ilimitados vínculos com igual intensidade. Assim, a afirmação poliamorista de que todos são igualmente únicos promove uma aparente e paradoxal conciliação entre os valores de igualdade e diferença, na qual são ressaltadas as individualidades, mas recusadas as hierarquias.

\section{Referências bibliográficas}

ANAPOL, Deborah. Polyamory: The New Love without Limits. San Rafael, CA, IntiNet Resource Center, 1997.

BADINTER, Elizabeth. Um é o Outro. Rio de Janeiro, Nova Fronteira, 1986.

BARKER, Meg e LANGDRIDGE, Darren.Whatever happened to nonmonogamies? Critical reflections on recent research and theory.Sexualities 13(6), 2010, pp.748-772.

BUTLER, Judith. Problemas de gênero: feminismo e subversão de gênero. Rio de Janeiro, Civilização Brasileira, 2010.

CARDOSO, Daniel. Amando vári@s - Individualização, redes, ética e poliamor. Dissertação de mestrado, Universidade Nova de Lisboa, 2010.

DUMONT, Louis. Gênese I: do Indivíduo-fora-do-mundo ao Indivíduo-nomundo. In: DUMONT, Louis. O Individualismo: uma perspectiva 
antropológica da ideologia moderna. Rio de Janeiro, Rocco, 1985, pp.201-225.

ELLIS, Havelock. Studies in the Psychology of Sex. Sex in Relation to Society, v. 6, 1927.

FÉRES-CARNEIRO, Terezinha. Conjugalidades contemporâneas: um estudo sobre os múltiplos arranjos conjugais da atualidade. Disponível em: $<w w w . f u n d a m e n t a l p s y c h o p a t h o l o g y . o r g>$. Acesso em: 13 de agosto de 2011.

Figueira, Sérvulo Augusto. O contexto social da psicanálise. Rio de Janeiro, Livraria Francisco Alves, 1981.

GIDDENS, Anthony. A transformação da Intimidade. Sexualidade, Amor e Erotismo nas Sociedades Modernas. São Paulo, Universidade Estadual de São Paulo, 1993.

GOLDENBERG, Mirian (Org.).Os Novos Desejos:seis visões sobre mudanças de comportamento de homens e mulheres na cultura brasileira contemporânea. Rio de Janeiro, Record, 2000.

. Porque homens e mulheres traem? Rio de Janeiro, Best bolso, 2010.

HARITAWORN, Jin;Lin, Chin-ju;Klesse, Christian. Poly/logue: A Critical Introduction to Polyamory. Sexualities, 9(5), 2006, pp.515-529.

HeILBORN, Maria Luiza. Dois é par: gênero e identidade sexual em contexto igualitário. Rio de Janeiro, Garamond, 2004.

KLESSE, Christian. Polyamory and its "others": contesting the terms of non-monogamy. Sexualities, v.9, n.5, 2006, pp.565-583.

. Notions of Love in Polyamory - Elements in a Discourse on Multiple Loving. Laboratorium, vol. 3, n 2, 2011, pp.4-25.

LÉVI-STRAuSS, Claude. As estruturas elementares de parentesco. Petrópolis, Vozes. 1976.

LIBBY, Roger e WHITEHURST, Robert. Marriage and Alternatives: Exploring Intimate Relationships.Scott, Foresman, 1977.

LINS, Regina Navarro. A cama na varanda. Arejando nossas ideias a respeito de amor e sexo. Edição revista e ampliada. Rio de Janeiro, Best Seller, 2010. 
MARCIANO, Teresa. Variant Family Forms in a World Perspective. The Family Coordinator, vol. 24, no 4 , 1975, pp.407-420.

MAUSS, Marcel. Ensaio sobre a dádiva. Forma e razão da troca nas sociedades arcaicas. In: . Sociologia e Antropologia. vol. II. São Paulo, Edusp, 1974.

Morgan, Lewis Henry. Ancient Society Or Researches in the Lines of Human Progress from Savagery through Barbarism to Civilization. Calcutta,Bharti Library, 1944.

O’NeIL, Nena e O'NeIL George. Open Marriage: A New Life Style for Couples. New York, Evans \& Company, 1972.

PILÃO, Antonio. Poliamor e monogamia: construindo diferenças e hierarquias. Ártemis, vol. 13, jan-julho 2012, pp.62-71.

SALEM, Tânia. O casal igualitário: princípios e impasses. Revista Brasileira de Ciências Sociais, vol. 3, nº 9, fev. 1989, pp.24-37.

Simmel, Georg. The Sociology of Georg Simmel. New York, Free Press, 1950. . On individuality and social forms. Chicago, University of Chicago Press, 1971.

SuSSMAN, Marvin. The Four F's of Variant Family Forms and Marriage Styles.The Family Coordinator, vol. 24, nº 4, 1975, pp.563-576.

WAKE, Staniland. The development of marriage and kinship. Londres, George Headway, 1889.

WeSTERMARCK, Edvard. The History of Human Marriage. Londres, MacMillan. 1891.

. The Future of Marriage in Western Civilisation. Londres, MacMillan, 1936.

WILKINSON, Eleanor. What's Queer about Non-monogamy Now? In: BARKER, Meg and LANGDRIDGE, Darran (Ed.).Understanding NonMonogamies. London, UK, Routledge, 2010, pp.243-254.

WitTig, Monique. The Point of View: Universal or Particular? Feminist issues, vol.3, $n^{\circ} 2,1983$, pp.63-69.

WOLFE, Leanna. Jealousy and transformation in polyamorous relationships. Dissertação. The Institute for Advanced Study of Human Sexuality San Francisco, California, 2003. 